\title{
Tension stiffening approach in concrete of tensioned members
}

\author{
Salah Khalfallah* and Dahbia Guerdouh
}

\begin{abstract}
This paper presents an analytical model to calibrate the tension stiffening effect of tensile reinforced concrete members. The tension stiffening behaviour is a primordial task in reinforced concrete mechanic field. In this model, the stress-strain relationship of the tension stiffening effect described in the cracking range is proposed. The application of the analytical expression for tensile reinforced concrete member aims principally to quantify the tension stiffening phenomenon in the cracking range. In this concern, a parametrical study is established, which concerns the influence of concrete strength, reinforcement ratio, bar diameter and instantaneous properties of concrete on the tension stiffening behaviour. The obtained results relative to the influence of different parameters of the analysis are shown and commented.
\end{abstract}

Keywords: Tension stiffening; Analytical model; Nonlinear analysis; Tensile members; Bar diameter; Reinforcement ratio

\section{Introduction}

The intact concrete between adjacent cracks can still carry tensile stresses after cracking occurs in reinforced concrete members. This phenomenon known as the tension stiffening is principally generated due to the bond between reinforcing bars and surrounding concrete. Cracking and tension stiffening are considered among the complex phenomena of reinforced concrete mechanics. In this subject, a variety of constitutive laws, many approaches and various techniques have already been proposed to predict tension stiffening behaviour in reinforced concrete (RC) and fibre-reinforced (FRP) concrete structure. Many works have been shown that neglecting tension stiffening could lead to soft structures. The economy in reinforcement when the tension stiffening effect is taken into account during the procedure of the design has been quantified.

Various models integrating the tension stiffening effect have been proposed to design the RC structures. Among the models, we can quote the model of Branson (1968), which represents the tension stiffening effect using an equivalent moment of inertia of the cracked section of the beam. This model is largely used by designers to

\footnotetext{
* Correspondence: khalfallah_s25@yahoo.com

Civil Engineering and Environment Laboratory, B.P 98 Ouled Aissa, University of Jijel, 18000, Jijel, Algeria
}

compute RC- and FRP-reinforced beam deflections. However, other models are based on the modification of constitutive laws of steel or the sectional area obtaining an effective area of the section.

These models have also been used in nonlinear analysis of pull-out tests and bent beams. In this scope, we can illustrate various works published in the literature: Gilbert and Warner model (1978), Choi and Cheung (1996) and the CEB manual design model (CEB 1985), and among those that modify the sectional area, such as ACI-440 (ACI Committee 2003) and Behfarnia (2009). Recently, many complex models based on the bond-slip mechanisms between concrete and reinforcing bars have been published: Khalfallah (2008), Gupta and Maestrini (1990), Kwak and Song (2002) and Ng et al. (2011). In these models, there are some limitations in applications because these approaches depend on the nature of the distribution functions of bond along the reinforcement axis, and it follows in general a series of complex integrations of the second differential equation of bond.

However, previous attempts have already been drawn to present more realistically the tension stiffening effect, assuming the modifications taken in steel stresses. Based on this concept, this work introduces a novel tension stiffening approach applied to tensile RC members. The proposed model uses a parabolic curve to describe the post-cracking region of tensile stress-strain relationship

\section{包 Springer}

2014 Salah and Dahbia; licensee Springer. This is an open access article distributed under the terms of the Creative Commons Attribution License (http://creativecommons.org/licenses/by/2.0), which permits unrestricted use, distribution, and reproduction in any medium, provided the original work is properly cited. 
of reinforcing bars, improving the CEB tension stiffening model (CEB 1985). In addition, the influence of concrete strength, reinforcement ratio, bar diameter and instantaneous properties of concrete on the tension stiffening behaviour is studied and commented.

\section{Methods}

\section{CEB model (1985)}

The CEB model developed for tensile RC members integrates the tension stiffening effect through an increase in reinforcement stiffness. The mechanism of cracking of RC members subjected to monotonic tensile loading is shown in Figure 1. The figure presents different regions of the structural behaviour of RC members: uncracked concrete (I), cracking concrete (II) and yielding of reinforcement (III). The CEB model adopts a stress-strain relationship of reinforcing bars in terms of an average strain expressed by strain of an uncracked section and that of a totality cracked one, respectively.

The average strain of reinforcement is expressed by

$$
\varepsilon_{\mathrm{sm}}=\varepsilon_{\mathrm{s} 2}-\Delta \varepsilon_{\mathrm{s}}
$$

where $\varepsilon_{\mathrm{s} 2}$ is the strain in bare bar, and $\Delta \varepsilon_{\mathrm{s}}$ is the difference between a totality cracked section and partially cracked reinforced concrete one (Figure 1).

In the CEB manual design (CEB 1985), the increment of steel strain $\Delta \varepsilon_{\mathrm{s}}$ based on experimental results is given as

$$
\Delta \varepsilon_{\mathrm{s}}=\Delta \varepsilon_{\mathrm{s} \max } \frac{\sigma_{\mathrm{sr}}}{\sigma_{\mathrm{s} 2}}
$$

$\sigma_{\mathrm{s} 2}$ and $\sigma_{\mathrm{sr}}$ are the stress in bare bar and that corresponds to the cracked section level when the maximum stress in concrete reaches the strength of concrete in tension, and $\varepsilon_{\mathrm{smax}}$ is the maximum strain, defined as the difference between strains $\varepsilon_{\mathrm{s} 1}$ and $\varepsilon_{\mathrm{s} 2}$, which occurs at the beginning of the cracking process.

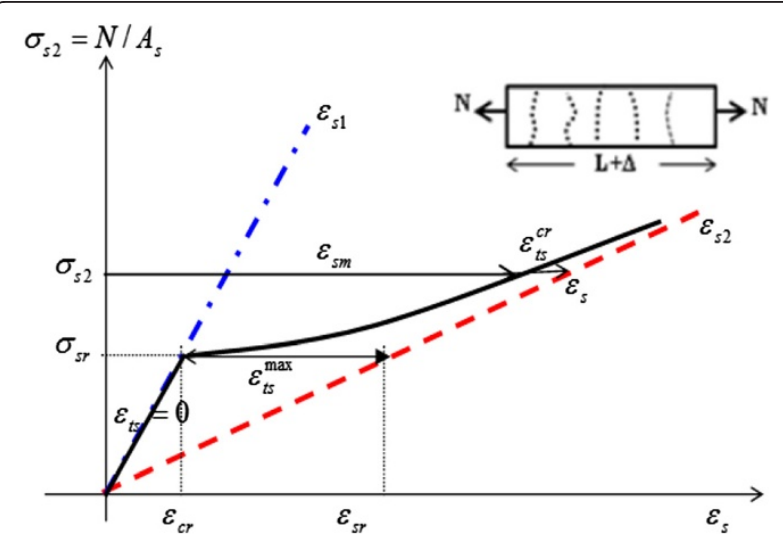

Figure 1 Tension stiffening behaviour of the tensile members.
An efficient tension stiffening model for nonlinear analysis of reinforced concrete members has been published by Stramandinoli and La Rovere (2008) where in the relationship (1) has been developed in function of the uncracked section $\varepsilon_{\mathrm{s} 1}$ and the full-cracked section of the member $\varepsilon_{\mathrm{s} 2}$.

$$
\varepsilon_{\mathrm{sm}}=\left(\frac{\sigma_{\mathrm{sr}}}{\sigma_{\mathrm{s} 2}}\right)^{2} \varepsilon_{\mathrm{s} 1}+\left[1-\left(\frac{\sigma_{\mathrm{sr}}}{\sigma_{\mathrm{s} 2}}\right)^{2}\right] \varepsilon_{\mathrm{s} 2} .
$$

The CEB model presents a consistent theory of the post-cracking behaviour of the RC members under pure tension. The corresponding curve is characterized as a bi-linear branch adopted in the cracking of concrete region.

\section{Proposed model}

A novel expression that describes the tension stiffening behaviour for structural members is proposed in this section. The model is based on the modification of the stress-strain formula of reinforcing bars as shown below.

The concrete is assumed to behave like a linear-elastic material until its tensile strength is reached. When the applied load, $N$, is relatively small, the strains in steel and in concrete maintain a single value. In this phase, the strain is then given by

$$
\varepsilon=\varepsilon_{s}=\varepsilon_{c}=\frac{N}{A_{s} E_{s}+A_{c} E_{c}}
$$

$E_{\mathrm{s}}$ and $E_{\mathrm{c}}$ are elastic modulus of the reinforcing bars and concrete before cracking, respectively. $A_{\mathrm{s}}$ and $A_{\mathrm{c}}$ are the reinforcement and the concrete area, respectively, and $N$ is the tensile applied load.

Until the formation of the primary crack of concrete, the components of the composite material change its behaviour due to the initiation and propagation of cracking mechanism. At this level, the stress value of reinforcing bars is calculated basing on the notion of the cracked section, where the maximum stress in the concrete under tension reaches its strength one. Equation (4) deals then to:

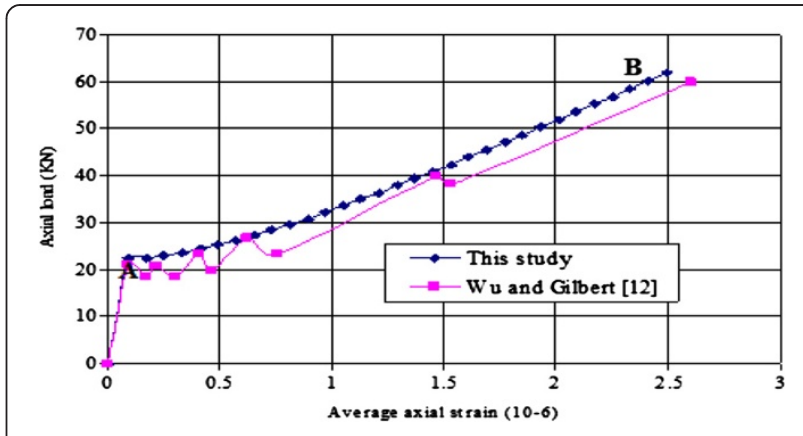

Figure 2 Load versus average strain under monotonic loading. 
Table 1 Details of the test specimens (Wu and Gilbert 2009)

\begin{tabular}{ccccc}
\hline Specimen & Concrete strength $(\mathbf{M P a})$ & Bar diameter, $\boldsymbol{D}(\mathbf{m m})$ & Dimension, $\boldsymbol{b} \times \boldsymbol{d} \times \mathbf{1}(\mathbf{m m})$ & Reinforcement ratio $(\boldsymbol{\rho} \%)$ \\
\hline G21 & 21 & $\mathbf{1 2}$ & $100 \times 100 \times 1100$ & 1.13 \\
G40 & 40 & $\mathbf{2 0}$ & $100 \times 100 \times 1100$ & 3.14 \\
\hline
\end{tabular}

$$
\sigma_{\mathrm{sr}}=\frac{1+\eta \rho}{\rho} f_{t}
$$

$\rho=\frac{A_{\mathrm{s}}}{A_{\mathrm{c}}}$ is the reinforcement ratio, $\eta=\frac{E_{\mathrm{s}}}{E_{\mathrm{c}}}$, and $f_{\mathrm{t}}$ is the tensile strength of concrete.

The modification added to the CEB model founded on a bi-linear law in the cracking range cannot represent well the structural behaviour of the RC tensile members. For this reason, a novel expression improving the CEB model is proposed. Due to the dominance of the material nonlinearity, it is to be noted that the heterogeneous composition of concrete, the introduction of the tension stiffening effect, the bond phenomenon, the dowel action, etc. influence the nonlinearity of the $\mathrm{RC}$ member response. Basing on this concept, in the post-cracking region, a polynomial expression is formulated until yielding of reinforcing bars takes place. The stress-strain relationship of the bare bar is assumed as asymptotic straight of the curve representing the expression developed, minimizing the tension stiffening in the cracking region of the member behaviour. After cracking, the stress in the reinforcement steel between the primary cracking and the yielding of reinforcement is then expressed using the mathematical establishments of this concept by

$$
\sigma_{\mathrm{s}}=\frac{E_{\mathrm{s}}\left(\varepsilon_{\mathrm{sm}}-\varepsilon_{\mathrm{cr}}\right)^{2}}{\left(\varepsilon_{\mathrm{sm}}-\varepsilon_{\mathrm{cr}}\right)+\left(\varepsilon_{\mathrm{sr}}-\varepsilon_{\mathrm{cr}}\right)}+\sigma_{\mathrm{sr}}
$$

where $\varepsilon_{\mathrm{cr}}$ and $\varepsilon_{\mathrm{sr}}$ are the cracking strain and the strain in the reinforcement in state II with totally cracked section without any concrete contribution corresponding to the stress $\sigma_{\mathrm{sr}}$, respectively.

The corresponding strain can be drawn using Equation (6) as

$$
\varepsilon_{\mathrm{sm}}=\varepsilon_{\mathrm{cr}}+\frac{\left(\varepsilon_{\mathrm{s}}-\varepsilon_{\mathrm{sr}}\right)}{2}+\frac{1}{2} \sqrt{\left(\varepsilon_{\mathrm{s}}-\varepsilon_{\mathrm{sr}}\right)\left(\varepsilon_{\mathrm{s}}+3 \varepsilon_{\mathrm{sr}}-4 \varepsilon_{\mathrm{cr}}\right)},
$$

with

$$
\varepsilon_{\mathrm{s}}=\frac{N}{E_{\mathrm{s}} A_{\mathrm{s}}} .
$$

The tension stiffening contribution in the cracking range of concrete can then be evaluated by

$$
\varepsilon_{\mathrm{ts}}^{\mathrm{cr}}=\frac{\left(\varepsilon_{\mathrm{s}}+\varepsilon_{\mathrm{sr}}\right)}{2}-\varepsilon_{\mathrm{cr}}-\frac{1}{2} \sqrt{\left(\varepsilon_{\mathrm{s}}-\varepsilon_{\mathrm{sr}}\right)\left(\varepsilon_{\mathrm{s}}+3 \varepsilon_{\mathrm{sr}}-+\varepsilon_{\mathrm{cr}}\right)}
$$

Particularly, the maximum tension stiffening can be deduced as (Figure 1):

$$
\varepsilon_{\mathrm{ts}}^{\max }=\varepsilon_{\mathrm{sr}}-\varepsilon_{\mathrm{cr}} \text {. }
$$

\section{Results and discussion \\ Analytical model \\ Validation of the model}

To verify the validity of the proposed model, it is necessary to compare the obtained results with those already published in the literature. Experimental data that have been elaborated by Wu and Gilbert (2009) are chosen. In this case, the applied load versus average axial strain curve is shown in Figure 2. Wu and Gilbert have tested several reinforced concrete prisms submitted to an axial tension having a square cross-section of $100 \times 100 \mathrm{~mm}$ and $1,100 \mathrm{~mm}$ of long and containing a single reinforcing bar longitudinally running through the centroid of each cross-section. Material properties and dimensions of specimens are regrouped in Tables 1 and 2 . The tensile axial load was applied to the ends of the reinforcing bar protruding from each end of the concrete prism. Four of the specimens were tested under monotonically increasing deformation until yielding of the reinforcing steel bar (the short-term tests) (Wu and Gilbert 2009).

Firstly, basing on the comparison between the analytical model and the experimental results, it seems that the obtained curve using this approach shows well concordance with the experimental one (Figure 2).

Secondly, the cracking load obtained is $22.46 \mathrm{kN}$; it is 6.44\% higher than that obtained in $\mathrm{Wu}$ and Gilbert (2009). In this way, the ultimate load is evaluated as $61.81 \mathrm{kN}$; it is $3.01 \%$ higher than the experimental data that is quantified as $21.10 \mathrm{kN}$.

Table 2 Material properties (Wu and Gilbert 2009)

\begin{tabular}{cccccc}
\hline Property & \multicolumn{2}{c}{ Reinforcing bars } & & \multicolumn{2}{c}{ Concrete strength } \\
\cline { 2 - 3 } \cline { 5 - 6 } & $\mathbf{1 2} \mathbf{~} \mathbf{~ m}$ & $\mathbf{2 0 ~} \mathbf{~ m m}$ & & Grade $\mathbf{2 1}$ & Grade $\mathbf{4 0}$ \\
\hline Strength (MPa) & $\mathbf{5 0 0}$ & $\mathbf{5 0 0}$ & & 21 & 40 \\
Stiffness (GPa) & $\mathbf{2 0 0}$ & $\mathbf{2 0 0}$ & & 22.4 & 22.4 \\
Tensile strength (MPa) & - & - & & 2.04 & 3.80 \\
\hline
\end{tabular}


Prior to the uncracking region of the curve (Figure 2), the specimen is at its stiffest and the load-strain curve is assumed linear. When the first cracking occurs $\left(P=P_{\mathrm{cr}}=22.46 \mathrm{kN}\right)$, there is an abrupt change of stiffness that continues to degrade under increasing deformation as other cracks can occur in the cracking region (portion $\mathrm{AB}$ ). The phenomenon of cracking primordially influences on the overall response of tensile member and on the tension stiffening behaviour. For this reason, the curves show that as the load increases, the tension stiffening strain gradually reduces.

\section{Parametric study}

\section{Influence of reinforcement ratio}

It is very important to understand how the area of the concrete around bars can contribute to stiff RC tensile members. Figure 3 shows a comparison of reinforcement ratios on the tension stiffening effect. In this study, two grades of concrete are used, and the obtained results are shown in separate graphs:

Figure 3a illustrates grade $\mathrm{C} 21$ concrete, and Figure $3 \mathrm{~b}$ shows grade $\mathrm{C} 40$ concrete. The primordial remark, which can be observed, is that the tension stiffening increases with the decrease of the reinforcement ratio. In addition, the tension stiffening contribution is more pronounced with light reinforcement with high quality of concrete (Figure 4a,b).

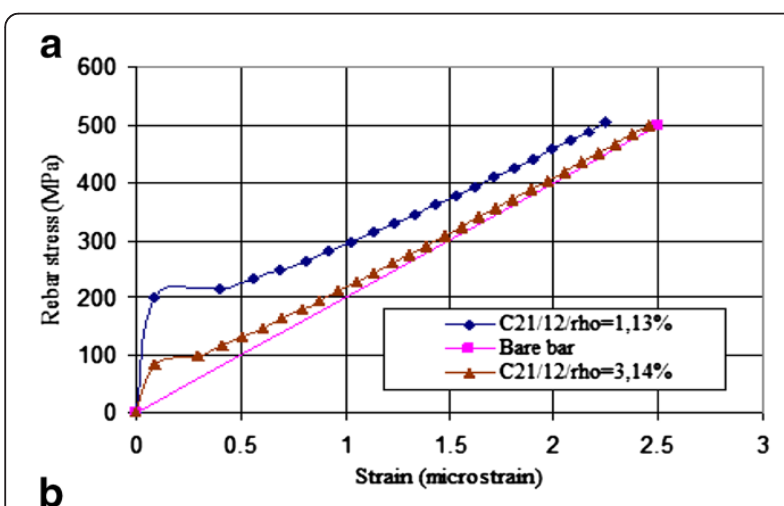

b

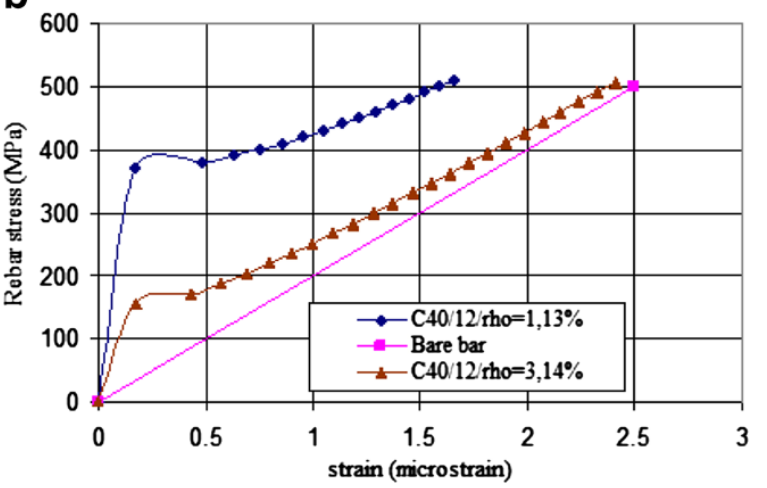

Figure 3 Influence of reinforcement ratio on the tension stiffening. (a) $\rho=1.13 \%$ and (b) $\rho=3.14 \%$.
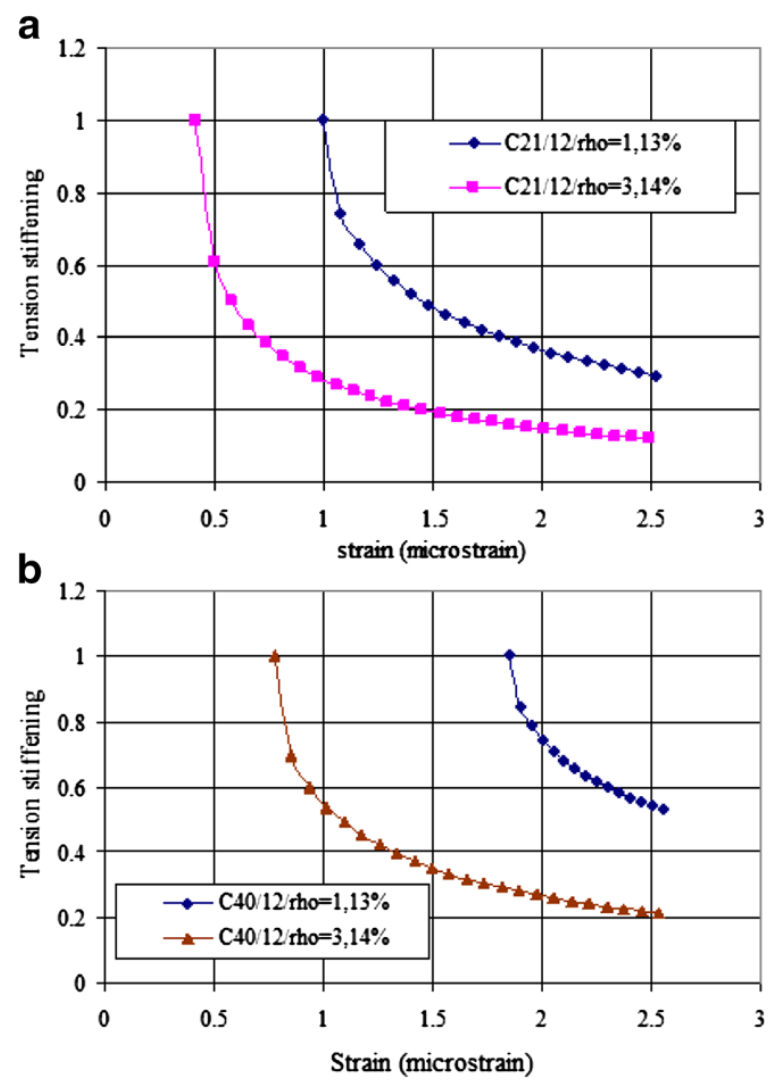

Figure 4 Influence of reinforcement ratios. (a) C21 grade and (b) C40 grade.

\section{Influence of concrete strength}

Figure $5 \mathrm{a}, \mathrm{b}$ compares the influence of concrete strength on the tension stiffening effect and on the response of specimens reinforced with different reinforcement ratios. The comparison clearly shows that the effect of tension stiffening at the cracking stage decreases with increasing concrete strength.

Figure 5 compares the influence of concrete strength on the responses of RC member having 12- and 20-mm bar sizes. This comparison shows that the effect of tension stiffening decreased with increasing concrete strength in the stabilized cracking stage (Figure 5a,b). Also, it is clear that high strengths of concrete reproduce great tension stiffening compared to low ones (Figure 6).

These results affirm other time results obtained by Perera and Mutsuyoshi (2011) and Kaklauskas and Gribniak (2011) which are opposite to the results from Abrishami and Mitchell (1996); the specimens with higher strengths of concrete exhibit a larger tension stiffening in the cracking stage.

\section{Influence of instantaneous modulus of concrete}

In this case, the instantaneous modulus of concrete has a neglected effect on the tension stiffening when the 


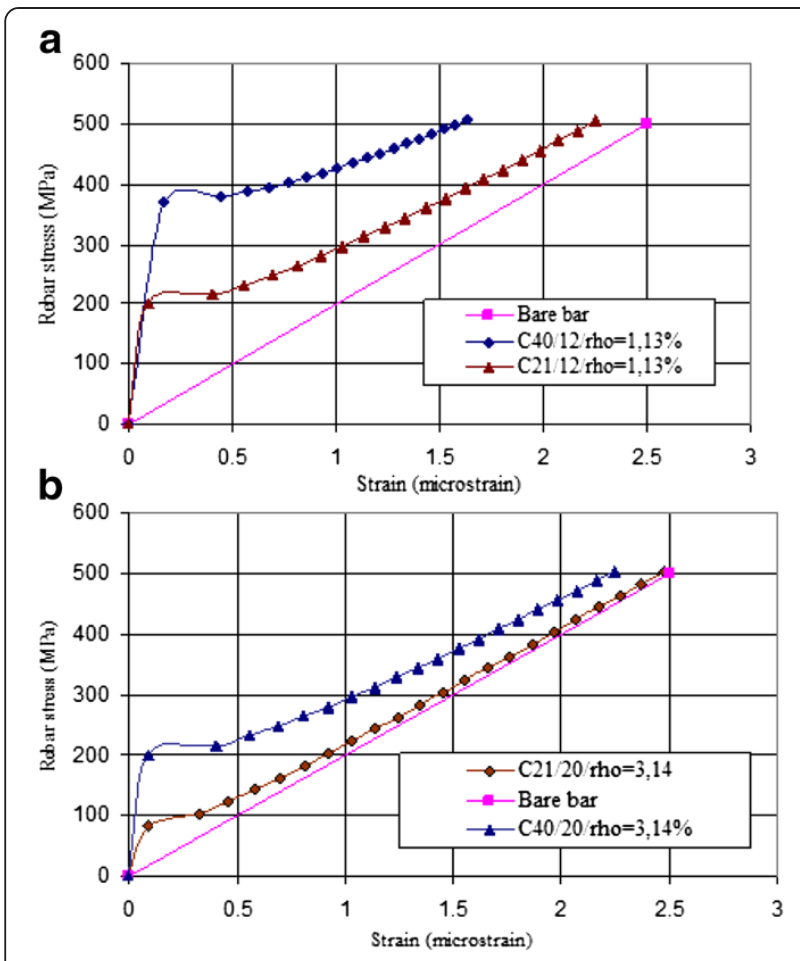

Figure 5 Influence of concrete strength on the tension stiffening. (a) $C 21$. (b) $C 40$

tensile members are weakly reinforced (Figures $7 \mathrm{a}$ and 8 ). But, a relative difference can be observed for members reinforced with higher reinforcement ratios.

\section{Conclusions}

In this study, an analytical expression of tension stiffening model for reinforced concrete members is presented. The relationship quantifying the tension stiffening is described using an average stress-average strain relationship in the cracking behaviour of the members. Firstly, the work presents the validity of the model described in

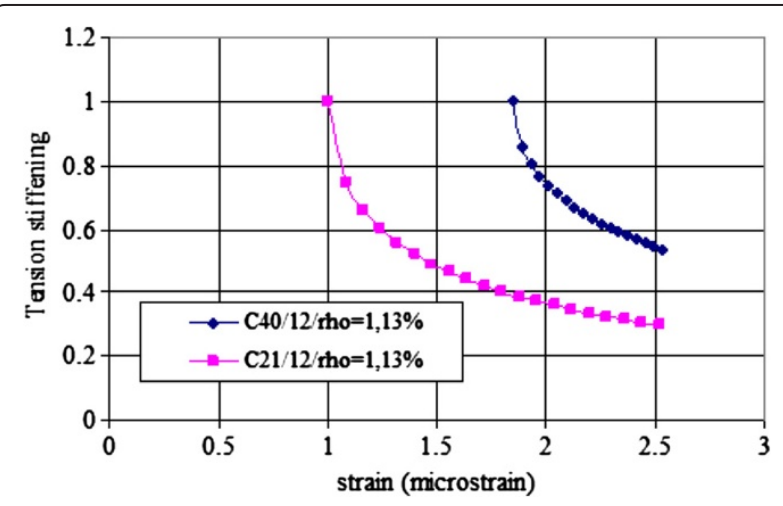

Figure 6 Influence of concrete strength.
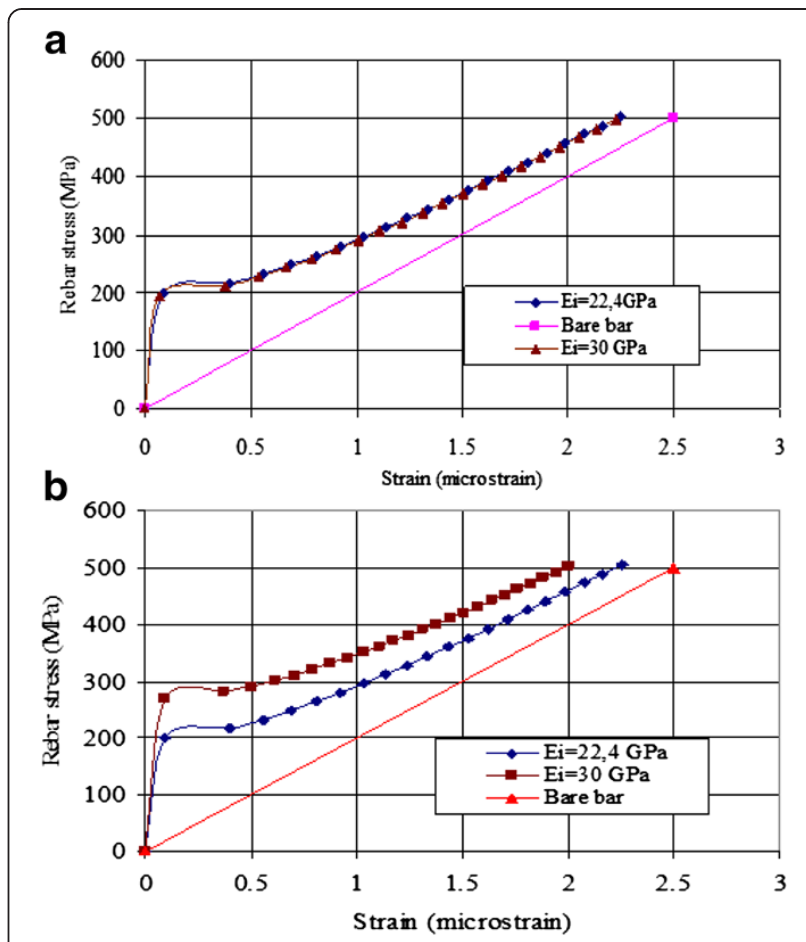

Figure 7 Influence of instantaneous modulus of concrete.

(a) $\varnothing=12 \mathrm{~mm}$. (b) $\varnothing=20 \mathrm{~mm}$.

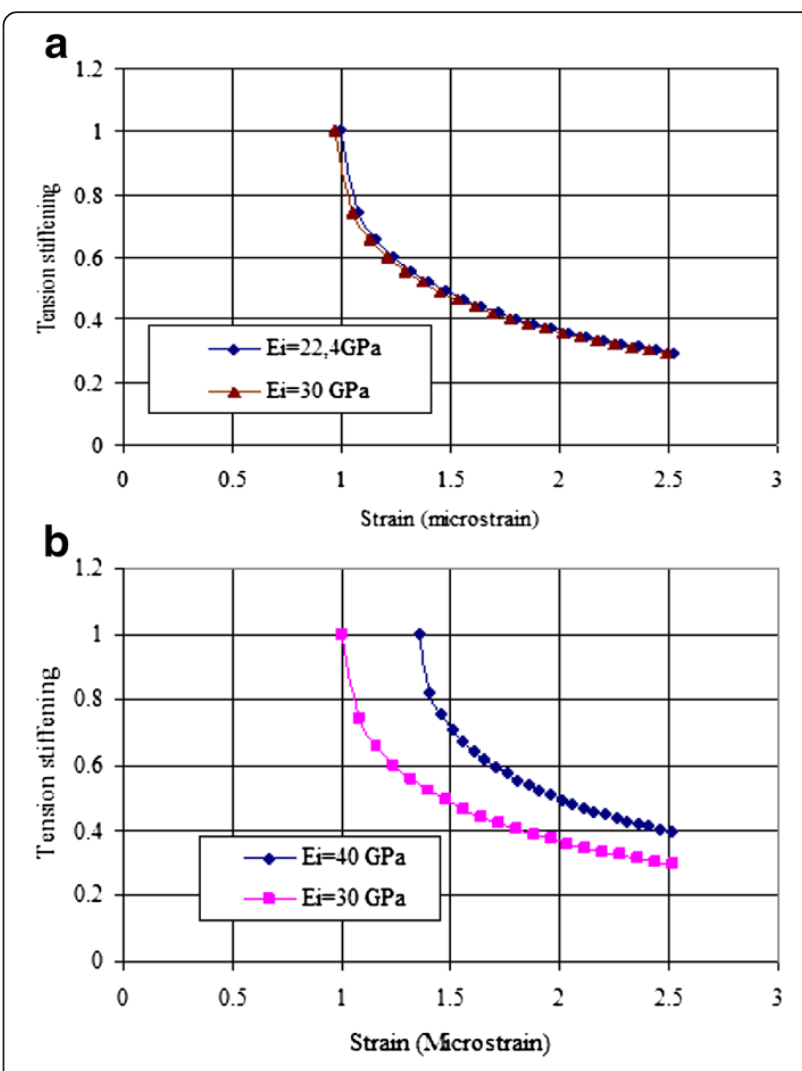

Figure 8 Influence of instantaneous concrete modulus. (a) C21 grade. (b) 40 grade. 
the sections above. Secondly, the tension stiffening behaviour was investigated using the proposed analytical expression of the tension stiffening contribution in the cracking range.

Based on the obtained results of this study, the following conclusions were drawn:

- Concrete strength and reinforcing ratio have an influence on the tension stiffening effect. The tension stiffening was more pronounced in members with small reinforcement ratios and with high strength of concrete.

- There is no significant influence on the tension stiffening behaviour using different instantaneous modulus of concrete and different bar diameters.

- High concrete strength and bar size can provide an important ultimate load of reinforced concrete members.

- The analysis requires the introduction of concretereinforcement bar bond features to understand more this aspect and to accurately predict the tension stiffening effect.

Competing interests

The authors declare that they have no competing interests.

\section{Authors' contributions}

KS has developed the model and GD has established the numerical examples. Both, KS and GD have written together conclusions. Both authors read and approved the final manuscript.

Received: 11 February 2013 Accepted: 9 December 2013

Published: 27 Jan 2014

\section{References}

Abrishami HH, Mitchell D (1996) Influence of splitting cracks on tension stiffening. ACI Struct J 93(6):703-710

ACl Committee 440, (2003) Guide for the design and construction of concrete reinforced with FRP bars (ACl 440.1R-03). Michigan: American Concrete Institute, Farmington Hills, pp 42

Behfarnia K (2009) The effect of tension stiffening on the behaviour of R/C beams. Asian J Civil Eng (Buil Housing) 10(3):243-255

Branson DE (1968) Design procedure for computing deflection. ACI Journal 65(8):730-742

CEB (1985) Cracking and deflection. Bulletin d'information No. 158. Comité Euro-International du Béton, Paris

Choi CK, Cheung SH (1996) Tension stiffening model for planar reinforced concrete members. Comput Struct 59(1):179-190

Gilbert RI, Warner RF (1978) Tension stiffening in reinforced concrete slabs. J Struct Div ASCE 104(2):1885-1900

Gupta A, Maestrini SR (1990) Tension stiffening model for reinforced concrete bars. J Struct Eng ASCE 116(3):769-791

Kaklauskas G, Gribniak V (2011) Average stress tension-stiffening relationship based on previous of design codes. Appl Phys Eng 12(10):731-736

Khalfallah S (2008) Tension stiffening bond modeling of cracked flexural reinforced concrete beams. J Civ Eng Manag 14(2):131-137

Kwak HG, Song JY (2002) Cracking analysis of RC members using polynomial strain distribution function. Eng Struct 24:455-468

Ng PL, Lam JYK, Kwan AKH, Kaklauskas G, Gribniak V, Bacinskas D (2011) Discussion: stiffening in concrete beams: part I: FE. Proc Insti Civil Eng Struct Build 164(6):433-435
Perera SVTJ, Mutsuyoshi DH (2011) Tension stiffening behavior of high-strength concrete tension members. Ann Res J SLSAJ 11(10):10-18

Stramandinoli RSB, La Rovere HL (2008) An efficient tension stiffening model for nonlinear analysis of reinforced concrete members. Eng Struct 30:2069-2080

Wu HQ, Gilbert RI (2009) Modeling short-term tension stiffening in reinforced concrete prisms using a continuum-based finite element model. Eng Struct 31:2380-2391

10.1186/2008-6695-6-2

Cite this article as: Khalfallah and Guerdouh: Tension stiffening approach in concrete of tensioned members. International Journal of Advanced

Structural Engineering 2014, 6:2

\section{Submit your manuscript to a SpringerOpen ${ }^{\circ}$ journal and benefit from:}

- Convenient online submission

- Rigorous peer review

- Immediate publication on acceptance

- Open access: articles freely available online

- High visibility within the field

- Retaining the copyright to your article

Submit your next manuscript at $>$ springeropen.com 